\title{
O Lebensraum na política externa russa para o Cáucaso do Sul (2000-2008)
}

\section{The Lebensraum in Russian foreign policy for the South Caucasus (2000-2008)}

\section{FÁBIO ALBERGARIA DE QUEIROZ RAQUEL SANTOS BACHIEGA}

\section{INTRODUÇÃO}

A ascensão da Rússia pós-soviética — ressalta-se, um tanto quanto inesperada (Bertonha 2009) - trouxe novas possibilidades e desafios quanto à distribuição de poder nas relações internacionais e, por conseguinte, no espaço geográfico eurasiático. A rápida subida ao poder de Vladimir Putin, um ex-membro da maior organização de serviços secretos da antiga União Soviética (a KGB, traduzida literalmente como "Comitê de Segurança do Estado"), trouxe novamente o Estado Russo aos holofotes da geopolítica, um cenário que historicamente nunca fora estranho ao "Império dos Czares", mas no qual poucos apostavam ver como um de seus protagonistas - pelo menos no curto prazo — o então combalido Kremlin.

Nesse sentido, as eleições russas dos anos 2000, que levaram Putin ao poder em substituição ao então presidente Boris Yeltsin, significaram "uma cisão profunda no sistema político da Rússia pós-soviética e o início de uma nova época" (Bossen 2000, 7), sendo esta razão um dos principais fatores explicativos das mudanças políticas e geográficas projetadas pela Federação Russa.

Em âmbito regional, as relações entre o grande Estado herdeiro da maior parte das conquistas soviéticas e os novos países que se formaram ao seu redor têm tomado dois caminhos: a formação de alianças ou a procura pelo afastamento total. Essa situação se intensificou durante o Governo

Fábio Albergaria de Queiroz - Pós-Doutorado em Relações Internacionais (Universidade de Brasília), Professor Adjunto na Escola Superior de Guerra (ESG).

Raquel Santos Bachiega - Internacionalista; pesquisadora associada ao NUPRI/UCB (Núcleo de Pesquisa em Relações Internacionais/Universidade Católica de Brasília). 
Putin, uma vez que o novo presidente procurou projetar uma política externa mais invasiva e assertiva em relação aos seus vizinhos fronteiriços ou, no jargão da geopolítica russa, o Exterior Próximo. ${ }^{1}$

Dessa forma, o artigo propõe o resgate de um dos conceitos que primeiro definiram o campo de estudo da geopolítica - o Espaço Vital, ou Lebensraum - de modo a testar sua validade explicativa quando analisado sob o prisma das formulações de política externa da Rússia, durante os primeiros anos de Putin como presidente (2000-2008). ${ }^{2}$ Cabe ressaltar que não foi possível descrever ou mesmo aferir a aplicabilidade deste conceito por meio de documentos ou declarações oficiais que apontassem a familiaridade do corpo diplomático e dos militares russos com o conceito de Ratzel, principalmente devido à barreira linguística. Ainda assim, tal fato não inviabiliza o exercício de se buscar identificar, nas ações do ator em análise, conexões com os elementos basilares do conceito, ainda que dedutivamente.

Posto isso, o artigo visa estudar as projeções geopolíticas de Putin para a região do Cáucaso do Sul, ou Transcaucásia. ${ }^{3}$ Para tanto, a análise pretende responder à seguinte pergunta: no contexto do Governo Putin (20002008), é perceptível a aplicabilidade do conceito ratzeliano de Espaço Vital na formulação da política externa russa para a Transcaucásia?

O intuito é analisar a política externa russa para a Transcaucásia baseado na aplicabilidade da premissa expansionista encontrada na noção geopolítica de Espaço Vital. Adicionalmente, com a finalidade de melhor especificar o universo de análise, foi preciso escolher uma das regiões que fazem fronteira com a Rússia, configuradas em seu exterior próximo, assim como o recorte temporal a ser utilizado. A escolha da Transcaucásia deu-se pelo fato de a região ter sido, durante o Governo Putin, a questão mais complexa com a qual Moscou teve que lidar.

Para a realização da análise aqui proposta, faremos uma descrição histórica da construção do espaço russo para, então, comparando as inferências obtidas no recorte temporal selecionado, identificar semelhanças e diferenças (Lijphart 1971; Seawright and Collier 2004) nas iniciativas de Putin para cada país do Cáucaso do Sul (Geórgia, Armênia e Azerbaijão), de acordo com três variáveis: 1) a perspectiva de ameaça terrorista; 2) a exploração de recursos naturais e/ou energéticos; e 3) a projeção militar.

Para cumprir seu intento, o artigo encontra-se dividido em três partes, nos quais são desenvolvidos diferentes narrativas (histórica, teórica e empírica) em busca da consecução de três objetivos específicos: 1) a partir da perspectiva histórica da geopolítica, apresentar o conceito de Espaço Vital e sua aderência aos propósitos da política externa dos Estados; 2) buscar inferir a influência do conceito de Espaço Vital na construção do Estado 
Russo, por meio do estudo de sua formação histórica; e 3) verificar a aplicabilidade do conceito de Espaço Vital na formulação da política externa do Governo Putin (2000-2008) para cada país da Transcaucásia.

\section{O ESPAÇO VITAL COMO INSTRUMENTO DE POLÍTICA EXTERNA}

Não obstante as múltiplas vertentes da Geopolítica enquanto campo teórico-conceitual, é possível inferir haver um ponto de tangência entre a busca de elementos que expliquem o poder do espaço e, por conseguinte, as transformações do poder no espaço, ou em outras palavras, o alcance territorial das manifestações do poder de determinados atores.

Logo, faz-se igualmente necessário entender o papel da Geopolítica nos estudos de política externa que, para os propósitos deste artigo, será referenciada, tomando como base as contribuições de Russell (1990, 255), como a área particular da ação política dos governos, abrangendo três grandes dimensões: político-diplomático, militar-estratégica e econômica - e que se projeta no âmbito externo ante uma miríade de atores e instituições governamentais e não governamentais, o que nos leva, concomitantemente, a conceber a geopolítica a partir de uma estrutura relacional originada no trinômio espaço-poder-atores, tal qual nos aponta a Figura 1.

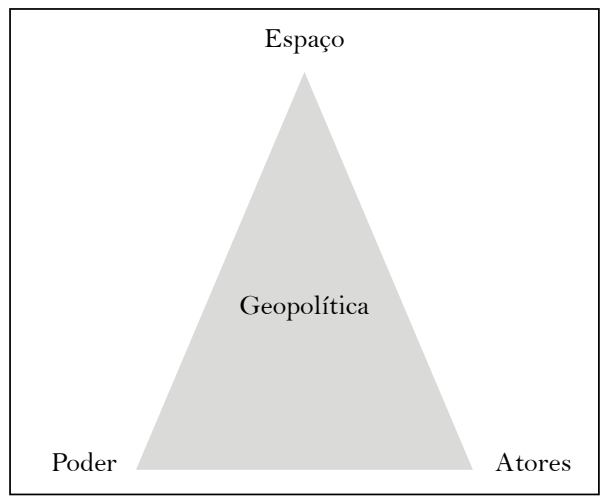

Figura 1 - Estrutura Relacional da Geopolítica Fonte: elaborado a partir de Russell (1990) e Raffestin (1993).

Supondo como válidas as premissas até aqui apresentadas, eis, então, uma questão sobre a qual devemos nos debruçar para alcançar nosso intento: como conectar espaço, poder e a agência dos atores em determina- 
do contexto a partir de um elemento comum? Uma possibilidade, aquela à qual recorremos, como dito, é o conceito de "Espaço Vital" (Lebensraum) cunhado por Friedrich Ratzel (1844-1904). Com Ratzel, inicia-se o estudo sistemático da dimensão geográfica da política, que tem como corolário basilar a premissa de que a expansão territorial de um povo é justificável se o espaço almejado for capaz de prover os meios para a satisfação de suas necessidades - portanto, a espacialidade, ou a territorialidade, do Estado era o principal objeto de preocupações. Essa premissa indicava a ideia do que seria o Estado e sua ligação com o território como uma fonte de poder - e passou a ser utilizado por líderes políticos como justificativa para aventuras expansionistas em busca do equilíbrio entre as necessidades de uma dada população e a disponibilidade de recursos que o meio oferece para supri-las.

Ratzel sugere, portanto, que a existência do Estado estaria diretamente relacionada à sua capacidade de controlar áreas estratégicas capazes de prover recursos vitais para o desenvolvimento e progresso social do Estado. Logo, Ratzel supõe que os Estados são concebidos a partir da profunda conexão com o espaço, sendo, pois, pragmaticamente indispensável a adoção do fundamento geográfico do poder político (Costa 2008, 34). ${ }^{4}$

Assim, torna-se compreensível a razão pela qual alguns autores que vieram depois de Ratzel (como o geopolítico francês Yves Lacoste) interpretaram a relação entre o papel do conceito de Espaço Vital e a política externa dos Estados como uma premissa expansionista. Portanto, voltando ao nosso ponto de partida, para o universo de pesquisa e o recorte temporal selecionados haveria uma relação de causalidade entre a ideia de Espaço Vital e os princípios da política externa de Putin? E, neste sentido, como se dariam as possíveis inter-relações entre essas duas variáveis?

\section{A CONSTRUÇÃO DO LEBENSRAUM RUSSO}

Entender o contexto e os condicionantes na construção do conceito de Lebensraum, bem como suas várias interpretações, será o exercício no qual nos debruçaremos doravante na tentativa de traçar o caminho de sua aplicação prática em termos de política externa, confirmando sua validade empírica e denotando a viabilidade de sua extensão a outros estudos de caso, como verificaremos adiante no processo de formação do Estado russo.

A Rússia, atualmente o maior Estado do mundo em extensão, conta com um vasto espaço territorial detentor de recursos naturais estratégicos, fato este que contribuiu para fazer deste ator, mesmo com as perdas sofridas na década de 1990, um player de primeira grandeza na geopolítica eurasiana. Não obstante seu status de potência continental, ao longo da história houve tentativas, por parte de países com pretensões hegemônicas, de conquistar 
o território russo, mesmo que, na maioria das vezes, a experiência tenha resultado em fracasso ${ }^{5}$ (Bertonha 2009; Queiroz 2013).

Entretanto, o que os fatos revelam é que esta vantagem geográfica ficou limitada à superfície continental, uma vez que as fronteiras russas não se estendem às costas marítimas navegáveis - seu acesso ao mar se restringe a águas que permanecem congeladas na maior parte do ano. Outro aspecto que, de certa forma, apresenta um grau de fragilidade da Rússia é a sua continentalidade, fator que, ao mesmo tempo em que é visto como uma vantagem regional, torna-se um elemento que dificulta a proteção de suas vastas fronteiras. ${ }^{6}$

Ao tentar amenizar essa vulnerabilidade ante possíveis fatores externos capazes de se apresentarem como ameaça ao Estado russo, a ideologia expansionista característica do país desde os séculos que levaram à sua consolidação resultou na anexação de territórios vizinhos, que passaram a formar o que a Rússia percebe como seu Espaço Vital.

Olhando para o processo de construção do Lebensraum russo a partir de uma retrospectiva histórica, merece destaque a expansão do território no século XVI com Ivan IV, o Terrível, período no qual o Estado em formação conseguia expandir-se em média 50 milhas quadradas diariamente, por vários anos (Kotkin 2016,2). Essa expansão ao leste foi relativamente rápida e sem muitos obstáculos, dado o fato de que as vastas áreas em questão eram pouco habitadas - circunstância observada mesmo hodiernamente, uma vez que a região da Sibéria se encontra despovoada salvo por algumas poucas cidades (Nygren 2008, 14).

Apesar disso, essa porção ao Leste carecia, como mencionado anteriormente, de uma saída para o mar quente, tornando-se uma preocupação do novo Estado desde o início de sua consolidação. Este componente só seria encontrado ao sul, como percebido por Pedro, o Grande (1672-1725), que promoveu a conquista da região com a tomada do norte do Mar Negro, no século XVII. Por conseguinte, a vitória de Catarina, a Grande (1729-1796) sobre o Império Otomano no século XVIII finalmente anexou a região do Mar Negro à Rússia, com a tomada da Crimeia em 1783 e de Odessa em 1791. Portanto, a expansão ao oeste provou-se crucial para o estabelecimento do Estado russo como uma grande potência. O término da Grande Guerra do Norte (1700-1721) proporcionou à Grande Rússia a atual Estônia e Letônia, bem como a Finlândia e a Bessarábia (atual Moldávia), em 1812, sendo essa expansão mais expressiva durante o reinado de Alexandre I (1777-1825).

Assim, de acordo com Nygren (2008, 16), a Rússia evoluiu "tanto no seu isolamento ante outros Estados (no leste), quanto na competição com outras grandes potências (no sul e no oeste), das quais algumas de suas 
características imperialistas se originam”. Portanto, a expansão territorial da Rússia foi, nas palavras de Dmitri Trenin (2001, 71), "determinada pela geografia, pelas circunstâncias históricas e pela mentalidade particular dos líderes russos".

Com o início da Primeira Guerra Mundial, em 1914, a Grande Rússia estava em seu pico territorial (ilustrado na Figura 2), estendendo-se dos mares Cáspio e Negro ao Oceano Pacífico, com uma população de mais de 145 milhões de habitantes e alcançando a quarta ou quinta posição no ranking de maiores economias industrializadas (Nygren 2008, 15; Kotkin 2016, 2). Foi na progressão da guerra, contudo, que o Estado russo percebeu sua fragilidade social (com a fracassada tentativa de unificação do Estado), econômica (com o retrocesso industrial, causado pelas elites) e militar (com o desastre no recrutamento e preparo da população) (Bertonha 2009).

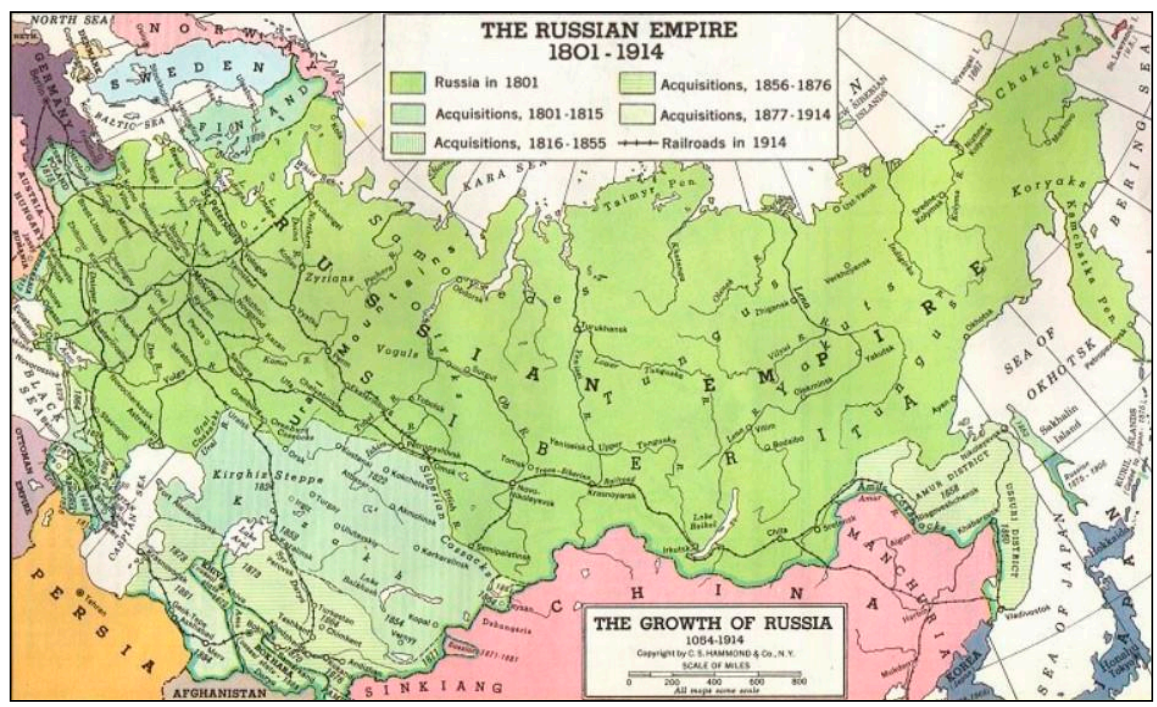

Figura 2 - O Império Russo (1801-1914).

Fonte: Hammond Historical Atlas (1965, 34).

Dessa forma, é indispensável pontuar que a Revolução Russa de 1917 daria início ao processo de reconquista política e geográfica do Espaço Vital russo, o que mais tarde levaria à criação da União das Repúblicas Socialistas Soviéticas. 


\section{O LEBENSRAUM SOVIÉTICO (1922-1991)}

$\mathrm{Na}$ visão Ratzeliana, os ideais políticos "expandem-se ou contraem-se com o espaço que os cerca”, sendo, pois, a política externa instrumento de consecução das demandas de uma comunidade nacional ali organizada. Logo, a noção de Espaço Vital, vista como uma geoestratégia de reestruturação do espaço, propõe a relação entre política externa e a tradição geopolítica de construção de uma identidade expansionista (Morozova 2011, 73).

A criação da URSS em 1922, portanto, refletiu a busca pela reconstrução tanto do antigo "espaço russo" quanto da identidade expansionista russa, alcançada inicialmente através do movimento político bolchevique de 1917. O primeiro Estado comunista da História retomou a atenção que a imensa Rússia recebia anteriormente às perdas físicas que sofrera com a Primeira Guerra Mundial, voltando a exercer uma efetiva influência no jogo de poder daquele momento (Bertonha 2009, 70-71).

Em termos geopolíticos, esse novo Estado procurou recuperar o que a velha Rússia havia perdido. A política externa russa, afiançada pelos corolários ratzelianos do Lebensraum, justificava as premissas expansionistas do Estado ao se utilizar de um horizonte ético abrangente das perspectivas de sua sociedade (Morozova 2011, 74).

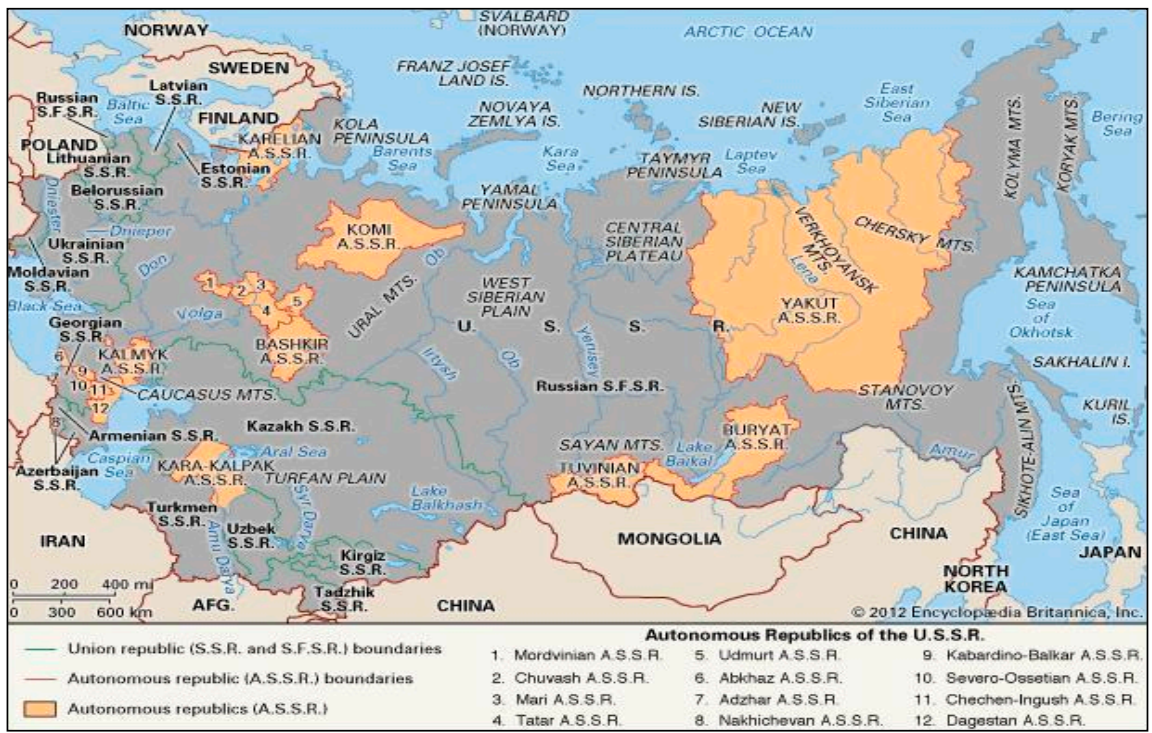

Figura 3 - A União das Repúblicas Socialistas Soviéticas (URSS).

Fonte: Encyclopaedia Britannica (2012). 
A unidade e coerência nacionais seriam mais tarde alcançadas, consideradas um produto do ambiente geográfico que cria condições similares de vida e atividade econômica ao longo do território (Morozova 2011, 75). Consequentemente, da interação entre uma sociedade e o território que esta ocupa, nasce, tal qual preconizado por Ratzel, o Estado orgânico - ente equiparado a um organismo vivo em busca do Espaço Vital à sua sobrevivência, justificando, portanto, a expansão como algo natural (Morozova 201 1, 74-75).

Por conseguinte, com o fim da Segunda Guerra Mundial e a instauração do período conhecido como Guerra Fria (1947-1991) — estágio que apresentou ao sistema internacional a dimensão do poder dos dois maiores atores à época, EUA e URSS - , essa nova realidade política passou a ser considerada como o apogeu do estudo das Relações Internacionais, elevando o reconhecimento da importância do pensamento geopolítico nas relações entre seu exterior próximo.

O desmantelamento do antigo bloco soviético, oficializado em 26 de dezembro de 1991, transformou a era de tensões que abalou o mundo por quase 50 anos (Bertonha 2009). Os países que compunham a URSS foram remetidos ao seu status anterior à anexação por Moscou, e a Rússia voltava agora à situação de instabilidade, especialmente geográfica.

Diversos atores moveram-se rapidamente para tentar integrar o quanto fosse possível do espólio soviético, absorvendo a Europa do Leste e persuadindo os Balcãs a entrarem para a Organização do Tratado do Atlântico Norte (OTAN), além da aproximação dos EUA com a Geórgia, o Cáucaso e vários países da Ásia central. A área estrategicamente mais sensível era - e continua sendo, dada a recente divergência na situação da Crimeia a Ucrânia, sendo esta a chave para um possível processo de desintegração do território russo e, consequentemente, do núcleo de seu Espaço Vital (Friedman 2009). Como explicado por Friedman (2009, 102), "given the simple fact that Russia did not disintegrate, the Russian geopolitical question will reemerge. Given the fact that Russia is now reenergizing itself, that question will come sooner rather than later".

Em vista destas percepções, a Rússia, a partir de então, tenta recompor o país, ao menos para que o reordenamento de forças no pós-Guerra Fria não signifique uma maior exposição de suas fronteiras, sobretudo por meio da adesão das ex-repúblicas soviéticas à aliança militar do ocidente.

\section{A CONSTRUÇÃO DO ESPAÇO VITAL RUSSO NO PÓS-GUERRA FRIA EM SEU EXTERIOR PRÓXIMO: O CASO DO CÁUCASO DO SUL}

Neste tópico serão delineadas as iniciativas de projeção de política externa do primeiro mandato de Vladimir Putin como presidente (2000- 
2008) para os países considerados pela Rússia como pertencentes ao seu exterior próximo. A seguinte análise, que destacará a região do Cáucaso do Sul, pretende relacionar as variáveis independentes russas para cada país aqui proposto (Geórgia, Armênia e Azerbaijão), utilizando-se da construção do Espaço Vital por meio da procura pela consolidação da Grande Rússia, sendo este um projeto estatal retomado, com ímpeto, por Putin por isso sua escolha como critério de análise.

Inicialmente, torna-se necessário entender a importância da região do Cáucaso para a Federação Russa, bem como a razão pela qual a execução dos projetos russos para seu exterior próximo - incluindo a Transcaucásia - se tornaram cada vez mais limitados. A vulnerabilidade de suas fronteiras no período pós-soviético tem contribuído para a diminuição de sua esfera imediata de influência, o que poderia vir a tornar o país mais vulnerável à perda de territórios e do espaço que este considera vital para a sobrevivência do Estado.

Anos após a dissolução da URSS, a questão geopolítica apresentava sinais de que voltaria com força na região. A retomada do pensamento russo mais tradicional e conservador, consolidado principalmente no ressurgimento da Teoria Eurasianista de Aleksandr Dugin, ${ }^{7}$ que passaria a integrar a sua nova política externa, aponta para uma combinação da percepção russa do Espaço Vital e da necessidade do Estado de manter sua identidade geopolítica - estas últimas baseadas na tradição histórica da Rússia de se determinar geograficamente. Tal feito é especialmente atribuído à organização russa Pamyat (que se autodetermina como o Movimento Popular Cristão Ortodoxo Patriótico-Nacional), uma vez que, nos anos 1990, esta abrangia a maior parte dos nacionalistas russos (Laruelle 2008, 4).

Ademais, torna-se importante recordar que a projeção de política externa da Rússia tem, do ponto de vista histórico, se focado primariamente nos países com os quais ela faz fronteira, partes constituintes da antiga União Soviética e atualmente pertencentes à Comunidade dos Estados Independentes (CEI). Essa estratégia regional enquadra-se nas medidas de segurança e manutenção da esfera geográfica de influência adotadas pelo Estado russo ao longo dos anos (Gorenburg 2016, 1).

A CEI é, além de Espaço Vital natural de afirmação russa, uma região onde são projetados interesses europeus, em particular, e ocidentais, em geral - sintetizados pela influência da União Europeia (UE) e OTAN. A esse respeito, Macedo $(2016,2)$ declara que "sendo o antigo espaço soviético, reconfigurado na CEI, o principal vetor da política externa russa, não deixa de estar intimamente ligado à dicotomia Leste-Ocidente”. Consequentemente, o alargamento dessas instituições ocidentais, que acontece desde o final da Guerra Fria, apresenta uma possível ameaça à influência e posicionamento da Rússia ante o sistema internacional (Macedo 2016, 2). 
Logo, o atual sentimento de insegurança que a Rússia apresenta possui similaridades com a situação de determinados períodos de sua história, uma vez que a Europa, embora não se apresente inamistosa - porém cautelosa —, pode não representar para a Eurásia uma entidade política cooperante (Queiroz e Krishna-Hensel 2019, 85;95); o Cáucaso, embora relativamente estabilizado durante o regime soviético, pode retornar à situação de possível desestabilização; a Ásia Central, além de sofrer pressões de atores externos, está em fase de desenvolvimento da sua própria identidade; e o Extremo Leste, que faz fronteira com a China, tem de lidar com as limitações impostas por uma superpotência ascendente (Fânzeres 2014, 19).

A adesão da República Tcheca, da Hungria e da Polônia em 1999, da Bulgária, Estônia, Letônia, Lituânia, Romênia e Eslováquia em 2004, e da Albânia em 2009 à aliança militar do ocidente colocou a administração da OTAN em uma região percebida pela Federação Russa como parte de seu Espaço Vital. Além do receio da proximidade da estrutura da OTAN frente às fronteiras russas, existe ainda a preocupação da Rússia de ser deixada de fora dos processos de segurança europeia (Macedo 2016, 53). O que se entendia era que o prestígio da Rússia, conquistado em anos de expansão política e geográfica, ficara paralisado. O conflito na Chechênia na década de 1990, que custou aos cofres russos pelo menos US $\$ 5$ bilhões e mergulhou o país em uma crise financeira, significou o limite da força e das condições russas de prevenir as incursões da OTAN em seu exterior próximo (Bandeira 2017, 23).

O Governo Yeltsin fora, portanto, caracterizado pela árdua transição de um Estado considerado como uma superpotência para um Estado ainda com status de potência militar — já que foi herdeiro do espólio soviético contudo, economicamente e politicamente fragilizado e com dificuldades de recuperação. Foi apenas com a chegada à presidência de seu primeiro-ministro Vladimir Putin, em 1999, que a agenda geopolítica do país voltaria a ser um elemento determinante da política externa russa. Em suma, a Rússia tem, factualmente, traçado sua expansão geopolítica para o continente europeu e asiático. Ao longo da história, esta se estendeu por quase todo o Cáucaso, considerada a região politicamente mais instável do exterior próximo russo.

\section{A IMPORTÂNCIA GEOPOLÍTICA DO CÁUCASO}

O Cáucaso, como mostrado na figura a seguir, está situado entre o Mar Negro e o Mar Cáspio, sendo uma das áreas mais etnicamente heterogêneas do mundo e a principal rota de migração entre a Europa e a Ásia ao longo dos séculos. A região sempre foi uma das mais eminentes arenas de 
guerra, cujo domínio foi disputado por russos, ${ }^{8}$ ingleses, persas e turcos no século XIX, alcançando relativa estabilidade apenas quando passou a fazer parte da União Soviética (Bandeira 2017, 2).

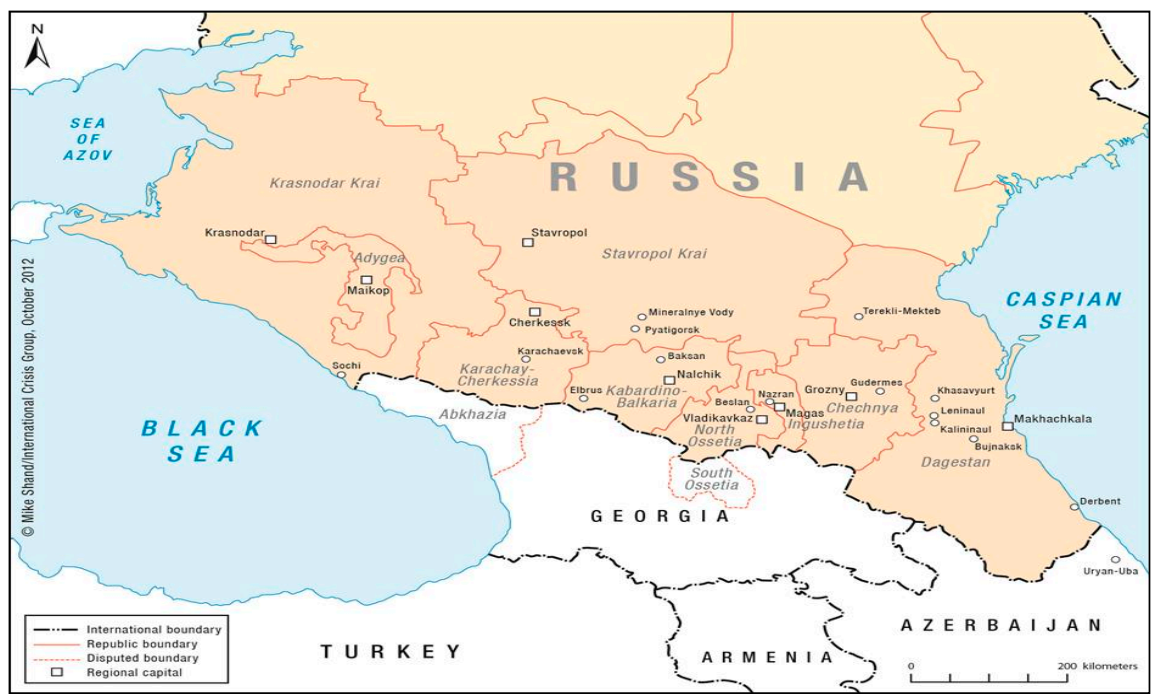

Figura 4-Mapa do Cáucaso (2012).

Fonte: International Crisis Group (2012, 33).

Além disso, o fim da União Soviética permitiu a criação de três novos Estados neste Espaço Vital (Geórgia, Armênia e Azerbaijão), que pertenceriam agora ao Cáucaso fora do domínio russo: o Cáucaso do Sul ou Transcaucásia. Consequentemente, a perda desse território, com a penetração econômica e militar dos EUA/OTAN, ${ }^{9}$ forçou o recuo da fronteira russa para o norte, mais vulnerável e instável, do Cáucaso, que compreende a Chechênia, a Inguchétia, o Daguestão, a Ossétia do Norte, a CarachaiCircássia, a Cabárdia-Balcária, a Adiguésia e o distrito de Krasnodar, formando assim o Cáucaso do Norte ou Ciscaucásia (Bandeira 2017, 3).

Cabe destacar ainda que o Cáucaso é um corredor vital para o transporte do petróleo do Mar Cáspio, assim como do gás da Ásia Central (ilustrado no mapa a seguir). Nesse sentido, o Estado da Geórgia, para a Europa, torna-se um parceiro fundamental para a estratégia de diversificação do fornecimento energético, enquanto os EUA o enxergam como peça essencial no Cáucaso para minimizar a influência russa resultante do transporte de gás para a Europa $^{10}$ (Alves 2012, 32). 


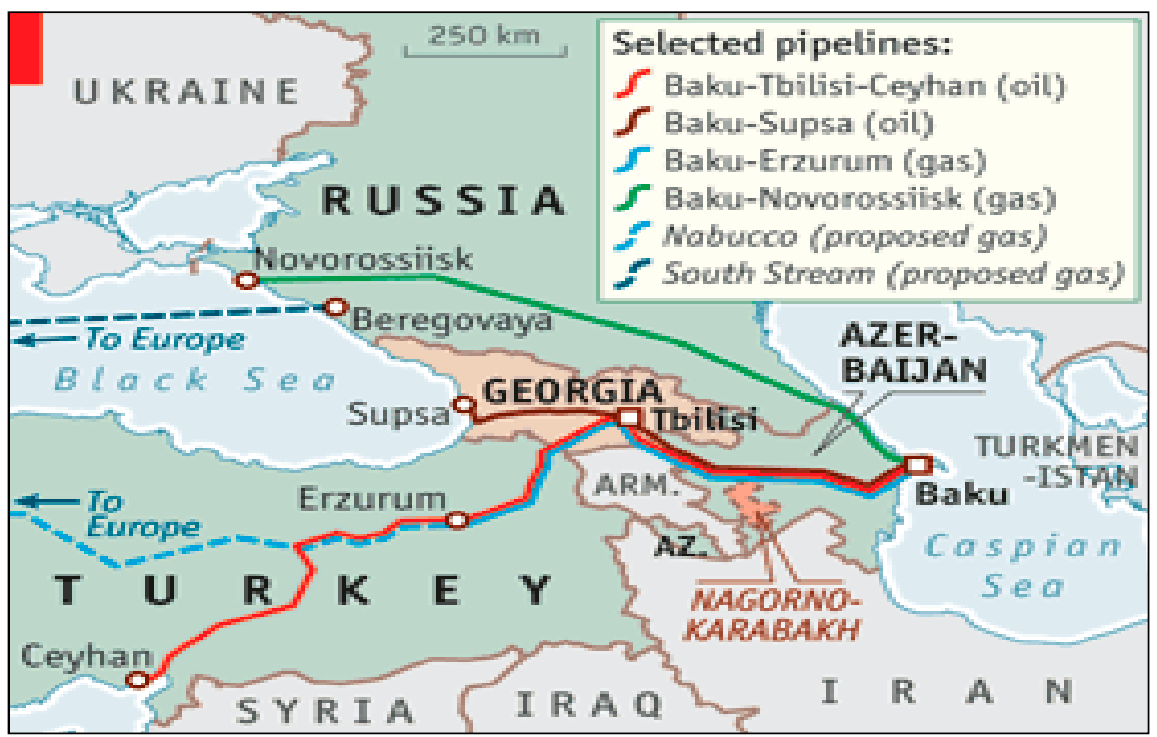

Figura 5 - Gasodutos do Cáucaso.

Fonte: The Economist (2008).

Complementarmente, o Cáucaso pode ser definido com parte de um conjunto de Complexos Regionais de Segurança ${ }^{11}$ (sub-complexo do Cáucaso/ Mar Cáspio/Mar Negro), sendo que a geopolítica desta região acaba por afetar não apenas o Espaço Vital russo, como também a segurança das três repúblicas da Geórgia, Azerbaijão e Armênia, que fazem fronteira com a Federação Russa (Nygren 2008, 101).

Seguindo a proposta do conceito de Lebensraum para justificar a política externa expansionista da Rússia pós-soviética, o exterior próximo russo mais interessante em termos geopolíticos seria, pelos motivos aqui sugeridos, o Cáucaso do Sul. Como veremos a seguir, os três países do Cáucaso do Sul sofreram, desde o início da década de 1990, várias investidas dos governos russos, que objetivavam manter a área sob sua esfera de projeção de poder e retomar o controle do território que a Rússia percebe como seu Espaço Vital, este perdido, como dito, com o fim da União Soviética.

\section{A POLÍTICA EXTERNA DO GOVERNO PUTIN PARA O CÁUCASO DO SUL}

O ponto de partida da administração de Putin, com a renúncia de Yeltsin, fora, portanto, a Segunda Guerra da Chechênia, em 1999. Desse modo, o primeiro mandato do Governo Putin seria repleto de traços da 
negligência ${ }^{12}$ da Era Yeltsin, especialmente na Chechênia, região que simboliza direta e indiretamente as tentativas do Estado de construir relações com os três países do Cáucaso do Sul em sua estratégia de reconquista de parte de seu Espaço Vital (Nygren 2008, 102).

Ambos os Cáucasos, do Norte e do Sul, passaram a ser vistos como regiões securitárias interligadas, sendo a estratégia de Moscou endossar que a segurança no Norte (no contexto do aumento de ataques organizados por tropas paramilitares islâmicas radicais na Inguchétia, CabárdiaBalcária, Carachai-Circássia e Ossétia do Norte) exigia uma ativa política russa no Sul (Secrieru 2006, 298).

Por conta do Tratado Turco-Russo de 192 1, a Rússia garante não apenas a fronteira com a Turquia, de um lado, e a Geórgia, Armênia e Azerbaijão, do outro; mas também o status das repúblicas autônomas de Ajaria (parte da Geórgia) e Nakhichevan (parte do Azerbaijão). Geopolíticos russos apontam ainda para a importância do Corredor de Megrin (na Armênia), que separa Nakhichevan do resto do território do Azerbaijão, impedindo, assim, uma conexão direta da Turquia com o Azerbaijão e o Mar Cáspio (Trenin 2001, 195).

Por conseguinte, a política externa russa para as citadas repúblicas do Cáucaso do Sul tem se concentrado em torno de três questões interconectadas: 1) primeiramente, a ameaça terrorista, utilizada como pretexto para se obter os resultados políticos desejados; 2) em segundo lugar, os interesses da Federação Russa e das companhias petrolíferas em uma perspectiva geoeconômica mais ampla (que resultaria na expansão dos negócios russos); e, por fim, 3) a habilidade da Rússia de projetar seu poderio militar para resolução de conflitos (manutenção de bases militares no Mar Cáspio) (Secrieru 2006, 298-299).

Antes mesmo dos ataques terroristas sofridos pelos Estados Unidos no 11 de Setembro 2001, período que significou para a Rússia o momento de lutar ao lado dos EUA contra um novo inimigo em comum, era evidente o receio do país quanto a uma possível ação das organizações do ocidente no Cáucaso do Sul (Nygren 2008, 103). Em março de 2000, o presidente armênio Robert Kocharian argumentou que as bases militares russas na Armênia e na Geórgia deveriam ser incorporadas por um sistema de segurança no Cáucaso do Sul, baseado no formato " $3+3+2$ " (um acordo entre a Armênia, o Azerbaijão e a Geórgia, com a Rússia, o Irã e a Turquia como fiadores e os EUA e a UE como patrocinadores) (Nygren 2008, 103).

Posto isto, quase um ano mais tarde, o Governo Putin lança uma ofensiva ao Cáucaso em janeiro de 2001. Em junho do mesmo ano, Putin tentou delinear iniciativas para se discutir as relações com o Cáucaso: o presidente russo encontrou-se primeiro com o presidente Kocharian da Armênia, em 
seguida com o presidente Aliev do Azerbaijão, e então com o presidente Shevardnadze da Geórgia, para discutir problemas regionais relacionados à segurança e conflitos não resolvidos, sugerindo aos países do Cáucaso do Sul que as relações entre as duas regiões haviam se tornado uma "prioridade da política externa russa” (Nygren 2008, 103).

Feita esta breve introdução quanto às relações entre a Rússia e a Transcaucásia em nível regional, analisamos, a seguir, em pormenores, a projeção russa para cada país da região, de acordo com as variáveis utilizadas pelo Governo Putin (2000-2008) que podem ser relacionadas à conquista do Espaço Vital e à consolidação territorial da Grande Rússia.

\section{a) Geórgia}

A Geórgia tem sido, pelos motivos que serão apresentados a seguir, a questão mais complexa da Transcaucásia, sendo determinante tanto para a Rússia quando para as instituições ocidentais.

Com a saída do presidente Clinton em 2001, o Pentágono moveu sua política externa em direção à Geórgia, procurando transformar o país em uma força de contenção para prevenir que a Rússia dominasse a região do Cáucaso novamente. Isso foi possível especialmente após os ataques do 11 de Setembro, quando o reeleito presidente georgiano Eduard Shevardnadze declarou a Washington sua pretensão de auxiliar os EUA na Guerra ao Terror. Na ocasião, Shevardnadze solicitou o apoio econômico e militar americano, além de assinar um acordo de parceria estratégica com a OTAN e permitir a construção do oleoduto de Baku-Tbilisi-Ceyhan (Bandeira 2017, 47).

O conflito de interesses com Moscou, no entanto, significou uma maior instabilidade para a Geórgia, principalmente após o reconhecimento russo da independência da Abcásia, uma região que declarou sua separação do Estado georgiano em 1992; e da instalação de bases militares russas nas áreas de Gudauta, na Abcásia, Batumi, na Ajaria, e Akhalkalaki, em Javakheti (Bandeira 2017, 47). A esse respeito, Trenin (2001, 191) declara que "the big issues [after the end of the Soviet Union] confronted the two countries indirectly, but in a very serious way. They relate to Abkhazia and South Ossetia, the two independent-minded regions inside Georgia, and Chechnya”.

Adicionalmente, a Rússia compartilha uma fronteira com a república separatista da Abcásia, na Geórgia, o que facilitou o envolvimento militar russo no conflito da região em 1992-1993. Desde então, essa fronteira tem proporcionado à Federação Russa um canal para exercer influência em seu Espaço Vital, mais especificamente na Abcásia e, indiretamente, na Geórgia (Trenin 2001, 191). 
Quanto à manutenção das fronteiras, o diálogo entre a Rússia e as autoridades abcasianas é constante, sendo esse esforço russo de manutenção da paz na linha de cessar-fogo entre a Abcásia e a Geórgia por vezes referida em Tbilisi como "guardas de fronteira para a Abcásia". Com o apoio militar russo aos separatistas da Abcásia, as forças georgianas foram derrotadas em 1993 e, desde então, Moscou tenta usar a questão da região para pressionar Tbilisi, ao mesmo tempo que rejeita pedidos de nacionalistas para anexar a Abcásia à Federação Russa (Trenin 2001, 191).

A outra questão conflituosa na Geórgia diz respeito à Ossétia do Sul, na qual as autoridades russas e o governo da Ossétia do Norte assumiram um papel moderador. Um batalhão russo, designado como "força de paz", é mantido na Ossétia do Sul, e a Rússia espera que qualquer acordo futuro na região preserve sua influência no território, seja diretamente ou pela Ossétia do Norte (Trenin 2001, 192).

Putin, claramente, projeta os interesses geopolíticos no país, sendo que o ápice dessa projeção aconteceu em agosto de 2008, com o ataque militar contra forças georgianas que invadiram a Ossétia do Sul. A ação serviu como um aviso, principalmente à OTAN, de que a região — o Cáucaso e as margens do Mar Negro - pertence à esfera russa de influência (mais precisamente, seu Lebensraum), não mais admitindo-se, portanto, uma maior penetração dos EUA e de forças ocidentais naquele espaço (Bandeira 2017, 61). Em retaliação, o então presidente americano George Bush declarou que a invasão da Ossétia do Sul era inaceitável, e o vice-presidente Dick Cheney afirmou que as ações russas não ficariam sem resposta. Mas ficaram, tanto na questão da Abcásia quanto da Ossétia do Sul (Bandeira 2017, 298).

Com a ajuda da Rússia, a resolução do conflito Ossétio-Georgiano tem sido tão lenta quando a do conflito abcasiano. A relação entre a Ossétia do Sul e a Geórgia pode ser, na melhor das hipóteses, um tanto tímida (Trenin 2001, 192). O diálogo entre Rússia e Geórgia no Governo Putin, no entanto, continua marcado pelos acontecimentos de 2008, período no qual a Geórgia sai da CEI, deixando de ser um membro efetivo da comunidade em 2009 (Macedo 2016, 78).

\section{b) Armênia}

Entre os três países que formam o Cáucaso do Sul, a Armênia é ainda aquele que mais depende da Rússia, seja no setor econômico ou no setor militar. Essa dependência provém da falta de recursos energéticos do país e do isolamento geográfico pelo qual a Armênia tem passado com o encerramento das fronteiras com o Azerbaijão e a Turquia, por conta do conflito de Nagorno-Karabakh ${ }^{13}$ (Macedo 2016, 96). 
As relações militares desenvolvidas entre Rússia e Armênia são importantes tanto para Moscou quanto para Erevan. Para os russos, estas relações significam a manutenção da Armênia em seu espaço vital; para os armênios, significa a garantia da segurança territorial (Macedo 2016, 96).

$\mathrm{Na}$ área militar, a Rússia continuou abastecendo os armênios com armamento pesado, enquanto na área econômica, o país conduziu uma política de apreensão de ativos em setores estratégicos do Estado armênio, por meio da exploração da dependência deste dos recursos naturais russos (Kelkitli 2008, 86). As relações militares e econômicas entre Armênia e Rússia foram aprofundadas especialmente após a revolução na Geórgia em 2003, uma vez que a Armênia continua hospedando várias bases e tropas russas em seu território, que guardam a fronteira armênia com a Turquia e o Irã. Com a crise política georgiana de 2003, os ministros da defesa da Rússia e da Armênia assinaram acordos de cooperação militar, sendo a Armênia considerada por Moscou um aliado estratégico no Cáucaso do Sul (Secrieru 2006, 299).

Outro ponto a ser destacado é que a Federação Russa tem assumido o controle de uma série de instituições econômicas da Armênia — ação não encontrou obstáculos, por conta de uma dívida de US $\$ 98$ milhões de dólares para a Rússia. Como parte do esquema, a Rússia recebeu ativos na área militar-industrial, como a usina térmica de Hrazdan, a fábrica eletrônica Mars e três empresas de pesquisa e produção, suficientes para liquidar de vez essa dívida externa (Secrieru 2006, 299).

Ao longo do Governo Putin (2000-2008), a tendência era aumentar a presença russa na Armênia. Desse modo, quase todo o complexo energético do Estado Armênio passou para o controle da estatal russa UES (Unified Energy System) (Secrieru 2006, 299).

No entanto, enquanto a Armênia oferece um ambiente amistoso para as tropas russas, geopoliticamente o Estado tem se transformado em uma ilha isolada, sendo que as forças russas - incluindo os guardas fronteiriços - estão se tornando mais vantajosos para o país hospedeiro do que para Moscou (Trenin 2001, 121).

\section{c) Azerbaijão}

As relações entre a Rússia e o Azerbaijão não são tão turbulentas quanto as relações russo-georgianas; no entanto, estão longe de serem tão amistosas quanto as relações entre Moscou e Erevan. Não existem disputas territoriais entre os dois países, mas a questão dos Lezghin (que, como os Ossétios, são um povo dividido pela fronteira com o Daguestão) e os conflitos em Karabakh se mostram como obstáculos tanto para essa relação bilateral quanto para a manutenção de influência russa em seu espaço vital (Trenin 2001, 191). 
O diálogo entre os dois países manteve o equilíbrio durante a Era Putin, uma vez que o Azerbaijão se mostra menos interessado em ingressar na OTAN do que a Geórgia, além de restringir seu apoio aos combatentes chechenos ao extremo. Essa relação encontra-se fundamentada principalmente na cooperação energética, sendo que ambos conseguiram resolver suas duas questões mais controversas envolvendo o status da estação de Gabala e a delimitação do Mar Cáspio (Kelkitli 2008, 82).

Putin reorientou a política externa russa para o Azerbaijão ao, pragmaticamente, aproximar-se do país durante a visita do presidente azerbaijano Geidar Aliev em 2002, ocasião na qual Baku estendeu a utilização da estação de Gabala pela Rússia por mais 10 anos (Secrieru 2006, 299).

A questão chechena no país, no entanto, agravou-se, a ponto de fechar o escritório administrativo do presidente rebelde Aslan Maskhadov na capital do Azerbaijão (Secrieru 2006, 299). Isso ocorreu graças ao bombardeio russo da cidade de Kimir, à participação de tropas militares russas na fronteira do Azerbaijão com a Armênia e à imposição de restrições de vistos aos cidadãos azerbaijanos pelo governo russo; estas ocorrências mudaram o rumo das relações entre os dois países a favor da Rússia, uma vez que o Azerbaijão extraditou vários combatentes chechenos para a Rússia e fechou centros escolares e culturais chechenos no país (Kelkitli 2008, 83).

Em 2002, Rússia e Azerbaijão chegaram a um acordo sobre a demarcação do solo oceânico do Mar Cáspio, além de retirarem formalmente a oposição à construção do gasoduto de Baku-Tbilisi-Ceyhan. Em 2004, o novo presidente azerbaijano, Ilham Aliev, visitou Moscou, ocasião na qual os dois Estados concordaram em expandir a cooperação militar bilateral (Secrieru 2006, 300).

Complementarmente, comparado aos outros dois Estados da Transcaucásia, o Azerbaijão é menos dependente do abastecimento energético russo, por conta de suas reservas naturais de gás e petróleo. E, apesar dos acordos firmados na esfera militar, estes ainda permanecem em dimensões limitadas (Kelkitli 2008, 85).

Logo, dos Estados da Transcaucásia, o Azerbaijão continua a ser o mais distante da esfera russa, condição que permaneceu mesmo com o fim do primeiro Governo Putin (2000-2008), e que vai em direção contrária aos intentos de Putin para a região.

\section{CONSIDERAÇÕES FINAIS}

As inferências causais e descritivas auferidas sugerem que a política externa russa para o espaço vital transcaucasiano, entre 2000 e 2008, pautou-se em uma agenda heterogênea. De forma a alcançar o território que, 
como descrito, historicamente considera como seu Lebensraum, a Rússia da Era Putin procurou manter e expandir sua presença na região, de modo que esta continuasse longe dos interesses ocidentais e, consequentemente, dentro do alcance russo.

Quanto à variável “ameaça terrorista”, utilizada como justificativa russa para a manutenção da segurança nacional e regional, esta fora eficiente para conter a influência dos rebeldes chechenos no Azerbaijão, ao mesmo tempo em que não surtiu efeito na Geórgia, que procurou integrar-se à OTAN. A Armênia, que, diferentemente do Azerbaijão, não apresenta diferenças religiosas com a Rússia (Geórgia e Armênia são de maioria cristã, enquanto o Azerbaijão, assim como grande parte do Cáucaso do Norte, é de maioria muçulmana), não foi movida pela questão terrorista, mantendo o foco no conflito fronteiriço ao leste.

Quanto aos interesses energéticos russos, esses pode ser observado na projeção para a Geórgia e para o Azerbaijão, enquanto a Armênia encontra-se dependente da Rússia no quesito dos recursos naturais. Este fato torna-se vantajoso para a Rússia, que encontra na Armênia um aliado fiel — e provavelmente o único — na região. Como explica Trenin (2001, 285), depois de anos de conflitos no Cáucaso do Sul, a Geórgia e o Azerbaijão passaram a ver a Rússia com desconfiança, enquanto a Armênia vê seu vizinho como um protetor externo. O Azerbaijão, por sua vez, usa da abundância de seus recursos para se afastar da influência de Moscou, mostrando-se o mais independente dos três Estados.

Por fim, a projeção militar russa foi ativa e proeminente nos três Estados ao sul, na medida em que a Geórgia, apesar de reticente, tem cedido às incursões militares mediante forte pressão do Kremlin. Dos três países, a Armênia apresenta o maior interesse na presença russa, especialmente em suas fronteiras com o Azerbaijão e a Turquia; e o Azerbaijão, apesar de concordar com a Rússia nos aspectos energéticos, contesta a influência russa em seu interior, acentuada pelo apoio do Kremlin à oposição armênia.

Assim, o que observamos dedutivamente, ressalte-se, é que a política externa de Putin procurou retomar a vocação expansionista do Estado Russo, utilizando-se, para tal, de premissas presentes no conceito de Espaço Vital para justificar suas ações na Transcaucásia. Cabe reafirmar que a análise geopolítica eurasiana não é recente ou mesmo rara. Portanto, uma vez explicado o conceito de Espaço Vital, bem como a relevância deste tipo de visão para a análise da formação dos Estados, buscou-se demonstrar a validade do tema (ainda que oriunda da geopolítica clássica do século XVIII) para as relações internacionais contemporâneas.

As inferências observadas permitiram-nos entender, em especial, como as relações da Federação Russa com cada país do Cáucaso do Sul diferem 
umas das outras, contrariamente à proposições que tratam as iniciativas para a região de maneira homogênea. Complementarmente, ao avaliar a aplicação do conceito de Espaço Vital na formulação da política externa, ainda que de maneira não expressamente objetiva, foi possível entender que as variáveis pelas quais o Estado procura se expandir podem ser inúmeras, indo muito além da concepção originalmente concebida na epistemologia do termo. Como exemplo, temos a variável étnica, que não chegou a ser considerada, mas que, certamente, merece maior espaço em estudos complementares.

Observamos que a questão energética, tão relevante para a Europa e para muitos vizinhos do Estado russo, bem como para a Geórgia e para o Azerbaijão, não pareceu ser, no escopo dos fatos apresentados, um fator determinante do interesse russo na Armênia, estando este embasado em outras variáveis. Similarmente, a Geórgia e a Armênia não são atingidas pela perspectiva de ameaça terrorista, enquanto o Azerbaijão está no foco de projeção das três questões analisadas.

Dessa forma, a aplicabilidade da noção de Espaço Vital na política externa russa é respaldada na projeção de determinadas variáveis, considerando que, em cada país do Cáucaso do Sul, o peso destas foi heterogêneo, como sintetizado na tabela seguinte.

\begin{tabular}{|c|c|c|c|}
\hline País & $\begin{array}{l}\text { Perspectiva de } \\
\text { ameaça terrorista }\end{array}$ & $\begin{array}{l}\text { Exploração de } \\
\text { recursos naturais } \\
\text { e/ou energéticos }\end{array}$ & Projeção militar \\
\hline Geórgia & Não & Sim & Sim \\
\hline Armênia & Não & Não & Sim \\
\hline Azerbaijão & Sim & Sim & Sim \\
\hline
\end{tabular}

Figura 6 - Projeção de política externa russa para os países do Cáucaso do Sul Fonte: Elaborado pelos autores.

Por fim, ainda que a partir de correlações dedutivas e, por conseguinte, limitadas quanto à sua capacidade explicativa, sugerimos que, com Putin, o Cáucaso do Sul continuou figurando como espaço vital na Realpolitik russa, mas por motivos que extrapolam a concepção original do modelo ratzeliano de Lebensraum. 


\section{REFERÊNCIAS}

Alves, André G. de M. P. (Org.). 2012. O Renascimento de uma potência?: a Rússia no século XXI. Brasília: IPEA.

Bandeira, Luiz A. M. 2017. The Second Cold War: Geopolitics and the Strategic Dimensions of the USA. Gewerbestrasse: Springer.

Bertonha, João F. 2009. Rússia: ascensão e queda de um Império. Curitiba: Juruá.

Bossen, Gerd D. et al. 2000. A Rússia no início da Era Putin. São Paulo: Fundação Konrad Adenauer.

Buzan, Barry, and Ole Wæver. 2003. Regions and Powers: the structure of International Security. Cambridge: Cambridge University Press.

Costa, Wanderley M. 2008. Geografia Política e Geopolítica. 2. ed. São Paulo: Edusp.

Encyclopaedia Britannica. 2018. The U.S.S.R. from fhe death of Lenin to the death of Stalin. https://www.britannica.com/place/Soviet-Union/The-U-S-S-R-fromthe-death-of-Lenin-to-the-death-of-Stalin.

Fânzeres, José M. F. 2014. Geopolítica e Geoestratégia da Federação Russa: a força da vontade, a arte do possível. Lisboa: Instituto da Defesa Nacional.

Friedman, George. 2009. The next 100 years: a forecast for the $21^{\text {st }}$ century. 1. ed. Nova Iorque: Doubleday.

Gorenburg, Dmitry. 2016. "Russia's Strategic Calculus: threat perceptions and military doctrine". PONARS Eurasia 448 (Nov.).

Hammond Incorporated. 1965. Hammond Historical Atlas. Maplewood: C. S. Hammond \& Company.

International Crisis Group. 2012. "The North Caucasus: the challenges of integration (I), ethnicity and conflict”. Europe Report 220 (Out.).

Ismailov, Eldar, and Vladimer Papava. 2010. Rethinking Central Eurasia. Singapura: Instituto Ásia Central-Cáucaso.

Kelkitli, Fatma A. 2008. "Russian foreign policy in South Caucasus under Putin". Perceptions 13 (Dez./Mar.).

Kotkin, Stephen. 2016. "Russia's perpetual Geopolitics". Foreign Affairs 95, no. 3 (Maio/Jun.). 
Laruelle, Marlène. 2008. Russian Eurasianism: an Ideology of Empire. Washington, D.C.: Woodrow Wilson Center Press.

Lijphart, Arend. 1971. "Comparative Politics and the Comparative Method". APSR 65, no 3 (September.).

Macedo, Mariana C. 2016. "A Política Externa Russa para os Países da Comunidade de Estados Independentes (CEI)”. 151 f. Dissertação (Mestrado) — Faculdade de Ciências Sociais e Humanas, Universidade Nova de Lisboa.

Morozova, Natalia. 2011. "The politics of russian post-soviet identity: geopolitics, Eurasianism, and beyond”. $227 \mathrm{f}$. Tese (Doutorado) - Departamento de Relações Internacionais e Estudos Europeus, Universidade Centro-Europeia.

Nygren, Bertil (Org.). 2008. The rebuilding of Greater Russia: Putin's foreign policy towards the CIS countries. Abingdon: Routledge.

Quadros, Marcos P. dos R., and Lauren Machado. 2015. "A Rússia e o Exterior Próximo: potencialidades e entraves para um projeto de grande potência". Brazilian Journal of International Relations 4, no 3.

Queiroz, Fábio A. 2013. "Revisitando o conceito clássico de segurança: dinâmicas, atores e validade analítica”. Intellector X, 1 (Online).

Queiroz, Fábio A, Krishna-Hensel, Sai F. 2019. A new Europe? Assessing challenges to the European Union Pluralistic Security Community. In: Queiroz, Fábio, Tomazini, Rosana, Platiau, Ana Flávia (eds.). Relações Internacionais da União Europeia: agendas e parcerias. Curitiba, Porto: Juruá.

2015. Geografia das Relações Internacionais. 165 slides. Material apresentado para a disciplina de Geografia Internacional no curso de Relações Internacionais da Universidade Católica de Brasília (UCB).

Raffestin, Claude. 1993. Por uma Geografia do Poder. São Paulo: Ática.

Russell, R. 1990. Política Exterior y Toma de decisiones en América Latina. Buenos Aires: GEL.

Seawright, Jason, and David Collier. 2004. Glossary. In: Brady, Henry, and David Collier. (eds.). Rethinking Social Inquiry: Diverse Tools, Shared Standards. Boulder, New York, Oxford: Rowman \& Littlefield Publishers.

Secrieru, Stanislav. 2006. "Russia’s foreign policy under Putin: 'CIS Project' renewed”. UNISCI Discussion Papers 10 (Jan.). 
Smith, Graham. 1999. "The masks of Proteus: Russia, geopolitical shift and the new Eurasianism”. The Royal Geographical Society, STOR 24, no. 4.

The Economist. 2008. Caucasian pipelines: The dangers of the safe route. https://www.economist.com/node/1 1920984/print? story_id=1 1920984\&CFI$\mathrm{D}=49989515 \&$ CFTOKEN $=33931025$.

Trenin, Dmitri. 2001. The end of Eurasia: Russia on the border between Geopolitics and Globalization. Washington, D.C.: Carnegie Moscow Center. 


\section{NOTAS}

1. Expressão que compreende o projeto russo de tornar-se uma grande potência, pressupondo o amplo domínio pela Rússia de suas regiões fronteiriças (território atualmente ocupado por Armênia, Azerbaijão, Bielorrússia, Cazaquistão, Estônia, Geórgia, Letônia, Lituânia, Moldávia, Tajiquistão, Turcomenistão, Ucrânia, Uzbequistão e Quirguistão), constituindo assim a legítima e histórica esfera de influência do país (Quadros e Machado 2015, 585-586).

2. Vladimir Putin chegou à presidência russa em 2000 e governou até 2008, quando Dmitry Medvedev venceu as eleições presidenciais após declarar que indicaria Putin (na época o político mais influente da Rússia) ao cargo de Primeiro-Ministro. Medvedev governou até 2012, sendo sucedido por Putin, que governa até os dias atuais (Macedo 2016).

3. Como explicado por Ismailov e Papava (2010, 7): "The disintegration of the Soviet Union not only gave rise to new independent states, a process of historic importance, but also formed the beginning of their integration into new geopolitical spaces. These spaces had their own geographical contours even within the former Soviet Union. This was reinforced by the economic zoning of the Soviet state on the basis of the administrative-territorial structure of the former U.S.S.R. Latvia, Lithuania, and Estonia together were called 'Pribaltika'; Azerbaijan, Georgia, and Armenia were known as the 'Trans-Caucasus'; while Kyrgyzstan, Tajikistan, Turkmenistan, and Uzbekistan together formed 'Sredniaia Azia' or Middle Asia”.

4. Apesar de assumirmos como corolário conceitual o Lebensraum ratzeliano, cumpre destacar o papel de abordagens contestatórias de suas premissas como o possibilismo, de Vidal de La Blache, que antagonizou a noção de espaço vital ao pressupor a existência de maneiras outras de desenvolver economicamente o Estado em um limitado espaço geográfico.

5. Caso emblemático foi a tentativa de invasão empreendida pela França napoleônica, que desafiou o equilíbrio europeu ao tentar a unificação do continente sob sua hegemonia. Vendo a ineficácia do Bloqueio Continental contra a Inglaterra (1806), Napoleão voltou-se em direção à Rússia disposto a conquistá-la. Napoleão adentrou suas fronteiras em 1812, com um exército de cerca de 600 mil homens. A longa marcha encontrou pelo caminho vastas planícies completamente devastadas pela resistência: era a tática da "terra arrasada". Ao chegar a Moscou com seu exército esgotado, Napoleão se deparou com o Czar Alexandre, até pouco tempo seu aliado, indisposto a fazer qualquer tipo de negociação. Diante das circunstâncias, e com a aproximação do rigoroso inverno 
russo, restou a Napoleão ordenar a retirada. Apenas 100 mil homens retornaram.

6. O que determina se uma potência é continental ou marítima é seu quociente de continentalidade, gerado a partir da relação entre a extensão da fronteira terrestre e a soma da extensão da fronteira terrestre com a extensão da fronteira marítima. Considera-se que, quanto maior a continentalidade de um Estado, menor será seu grau de liberdade e maior será a dependência de seus vizinhos, o que representa uma ameaça à sua soberania (Queiroz 2015).

7. A nova proposta do Eurasianismo, ou Neo-Eurasianismo, gradualmente deu forma ao Movimento Político Público e Universal da Eurásia, que mais tarde tornou-se o Movimento Eurasiano Internacional (Ismailov e Papava 2010, 30). Logo, a partir de 1993, o Neo-Eurasianismo passou a ser amplamente disseminado pelos dois maiores partidos nacionalistas à época, o Liberal-Democratic Party, ou Partido LiberalDemocrático (LDPR, em sua sigla em inglês), de Vladimir Zhirinovsky, e o Communist Party of the Russian Federation, ou Partido Comunista da Federação Russa (CPRF, em sua sigla em inglês), de Gennady Ziuganov. Ambos os líderes focaram nos aspectos geopolíticos do NeoEurasianismo, transformando-o em uma doutrina política (Laruelle 2008, 5-6). Deste modo, ao enfatizar a posição especial da Rússia como parte de uma distinta civilização eurasiana, o Neo-Eurasianismo estabelece a produção de uma teoria geopolítica específica que propõe sua visão do papel central da Rússia na Nova Ordem Mundial pós-Guerra Fria (Smith 1999, 483).

8. A conquista da região, iniciada com Pedro, o Grande, mostra sua vitalidade para a geopolítica da Rússia. Suas montanhas ao sul são consideradas como uma fortaleza natural na defesa da agricultura do norte (Bandeira 2017, 3).

9. Uma vez que a política em Washington ainda era guiada pela mentalidade da Guerra Fria e pelo triunfo da dissolução da URSS, o presidente americano à época, Bill Clinton, seguindo o Defense Planning Guidance (DPG) e violando os acordos anteriormente estabelecidos entre seu antecessor, George Bush, e o governante soviético Mikhail Gorbachev, expandiu a OTAN até as fronteiras da recém-criada Federação Russa, incorporando os Estados que pertenciam previamente à URSS, como a Estônia, a Lituânia e a Letônia. Os EUA também impuseram sua proeminência na região dos Balcãs, além de preencher o vácuo político no Cáucaso e na Ásia Central (Bandeira 2017, 22). 
10. A exemplo, tem-se o Traçado de Nabucco, grande projeto de gasoduto promovido pelos EUA que passa pelo território georgiano (Alves 2012, 32).

11. Como explicado por Buzan e Wæver (2003): "Um Complexo Regional de Segurança (CRS) é definido como um conjunto de unidades (geralmente Estados) cujos principais processos de securitização e dessecuritização, ou ambos, são tão interligados que seus problemas de segurança não podem ser razoavelmente analisados ou resolvidos de maneira separada. Um CRS toma forma a partir de três tipos de relações principais: 1) a distribuição de poder entre os Estados da região; 2) os padrões de amizade/inimizade entre os atores deste Complexo; 3) as relações de poder com atores externos à região. Alguns CRS, geralmente aqueles em que há um grande número de atores, contêm arranjos intermediários denominados Subcomplexos".

12. Como indicado por Nygren (2008, 102), "the Yeltsin era of RussiaCaucasian relations is full of aliance shifts and other developments out of control of official state authorities".

13. Como salienta Nygren (2008, 105): "The Nagorno-Karabakh conflict has been one of the most persistent ethnic violent conflicts since the demise of the USSR. Already in 1988, large demonstrations followed in Armenia after the refusal of USSR to transfer Nagorno-Karabakh (an enclave of a 200,000 majority of largely Christian Armenians within the territory of Muslim Azerbaijan) to Armenia from Azerbaijan where it had been since 1936. Azeris fled the enclave and Armenians in Azerbaijan were harassed, Azerbaijan closed its borders to Armenia and in December 1989 Armenia declared Nagorno-Karabakh part of Armenia”. 

(2000-2008)

\section{RESUMO}

As projeções de Vladimir Putin para o Cáucaso do Sul, considerada a área mais complexa do chamado exterior próximo entre 2000 e 2008, serão analisadas a partir do conceito de Espaço Vital, além de explicar a importância geopolítica do Cáucaso do Sul e as iniciativas do Governo Putin para a região.

Palavras-chave: Rússia; Cáucaso do Sul; Espaço Vital; Governo Putin.

\section{ABSTRACT}

Vladimir Putin's projections for the South Caucasus, considered the most complex area of the so-called near abroad between 2000 and 2008, will be analyzed from the concept of Lebensraum, in addition to explaining the geopolitical importance of the South Caucasus and the initiatives of the Putin Administration for the region.

Keywords: Russia; South Caucasus; Vital Space; Putin Administration. 